\title{
IDŐJÁRÁS
}

Quarterly Journal of the Hungarian Meteorological Service

Vol. 123, No. 2, April-June, 2019, pp. 217-240

\section{Detailed validation of EURO-CORDEX and Med-CORDEX regional climate model ensembles over the Carpathian Region}

\author{
Csaba Zsolt Torma \\ Department of Meteorology \\ Eötvös Loránd University and MTA Post-Doctoral Research Program \\ Pázmány Péter st. 1/A, H-1117 Budapest, Hungary \\ *Corresponding authorE-mail: tcsabi@caesar.elte.hu
}

(Manuscript received in final form September 24, 2018)

\begin{abstract}
Present study evaluates the ability of the ERA-Interim-driven regional climate model (RCM) simulations conducted in the framework of the Coordinated Regional Climate Downscaling Experiment (CORDEX) in describing precipitation and temperature climatic conditions over the Carpathian Region. In total, nine RCM simulations were assessed from EURO-CORDEX and Med-CORDEX (at $0.44^{\circ}$ and $0.11^{\circ}$ nominal resolutions) against the CARPATCLIM high resolution gridded observational database. Present work focuses on the mean, minimum, and maximum near-surface air temperature and precipitation. The study shows the performance of the members of RCM ensembles in representing the basic spatiotemporal patterns of the climate over the Carpathian Region for the period of 1989-2008. Different metrics covering from daily to monthly and from seasonal to annual time scales are analyzed over the region of interest: spatial patterns of seasonal mean temperature and precipitation, annual cycle of precipitation, monthly mean temperature bias, as well as climate indices, including CDD (consecutive dry days), R95, FD (frost days, when $\mathrm{T}_{\min }<0{ }^{\circ} \mathrm{C}$ ), and $\mathrm{SU}$ (summer days, when $\mathrm{T}_{\max }>25^{\circ} \mathrm{C}$ ). The results confirm the distinct capabilities of RCMs in capturing the local features of the climatic conditions of the Carpathian Region. This work is in favor to select RCMs with reasonable performance over the Carpathian Region, based on which a high-resolution bias-adjusted climatic database can be established for future risk assessment and impact studies.
\end{abstract}

Key-words: EURO-CORDEX, Med-CORDEX, CARPATCLIM, regional climate model evaluation, Carpathian Region, temperature, precipitation 


\section{Introduction}

Global or regional climate models can be useful tools for providing climate projections including information on human influence on climate and on climate change (IPCC, 2013). However, it is important to note that climate projections can be characterized by various kinds of uncertainties (Giorgi, 2005). Uncertainties arising from different model simulations, among others, can be attributed to internal variability (in the absence of any external radiative forcing), to the implemented parameterization and model dynamics (model or response uncertainty), or to the prescribed emission scenarios (scenario uncertainty). Regional climate model projections have inherent additional uncertainties due to the choice of integration domain, resolution, lateral boundary conditions (LBCs).

The evaluation of RCMs as members of ensembles has been recommended as a good practice (Beniston et al., 2007) to quantify the uncertainties and extract credible signals. Over the European continent, several RCM-based climate change projects have been accomplished in the last decades: (1) PRUDENCE (Predicting of Regional Scenarios and Uncertainties for Defining European Climate Change Risks and Effects, 2001-2004; Christensen and Christensen, 2007), (2) ENSEMBLES (Ensembles-Based Predictions of Climate Changes and Their Impacts, 2004-2009; Hewitt and Griggs, 2004), (3) CECILIA (Central and Eastern Europe Climate Change Impact and Vulnerability Assessment, 2006-2009; Halenka, 2007). The COordinated Regional Downscaling Experiment (CORDEX, Giorgi et al., 2009) is a more recent international initiative with the task of producing reliable regional climate simulations under the supervision of the World Climate Research Programme (WCRP, whose Task Force on Regional Climate Downscaling with a broader scientific community called for the aforementioned initiative). In the framework of CORDEX, several RCM experiments have been accomplished over different sub-regions of the globe. EURO-CORDEX (Jacob et al., 2013) and Med-CORDEX (Ruti et al., 2016) initiatives provide RCM simulations targeting European regions at grid resolutions of $0.44^{\circ}\left(\sim 50 \mathrm{~km}\right.$, medium resolution) and of $0.11^{\circ}(\sim 12 \mathrm{~km}$, high resolution). Two main guidelines are followed in designing the CORDEX RCM simulations according to the purposes: model assessment and regional climate projection (Giorgi et al., 2009; Jones et al., 2011). Under the model assessment experiments, the RCMs are driven by ERA-Interim reanalysis (Dee et al., 2011) providing the LBC, whilst in projections, RCMs are driven by selected GCMs serving climate change information through the twenty-first century.

This work is in favor of giving supporting information on selecting RCMs with good performance in different aspects over the Carpathians and its surrounding territories including the Carpathian Basin (the whole region hereafter referred as the Carpathian Region), and providing information on which a highresolution bias-adjusted climatic database can be established for risk assessment and impact studies for this region. Overarching aim of the author is to create a 
bias-adjusted database including precipitation and temperature data for the Carpathian Region, based on EURO- and Med-CORDEX regional climate model simulations using the CARPATCLIM dataset (Szalai et al., 2013) as reference. Initial steps towards this purpose are reported here.

The Carpathian Region expands between $44^{\circ}-50^{\circ}$ North and $17^{\circ}-27^{\circ}$ East. The Carpathians plays an important role in the climate of the Carpathian Region (i.e., by blocking cold air masses from the north), where warm dry Balkans meets with temperate Central Europe and cold continental Eastern Europe (UNEP, 2007). The climate across the Carpathian Region is influenced by oceanic, continental, and mediterranean effects, as well as by orographic factors. The region of interest has quite complex orography, including low lands and high mountain peaks with an altitude range between $27 \mathrm{~m}$ and $2655 \mathrm{~m}$ (Fig. 1). The CARPATCLIM dataset provides daily data over the following countries: Austria, Czech Republic, Croatia, Hungary, Poland, Romania, Serbia, Slovakia, and Ukraine with more than 20 million inhabitants living in that region. The Carpathian Region embraces a significant part of the drainage basins of the main rivers of this region: Danube and Tisza. Recent studies have been published with a special focus on the climate of the Carpathian Region considering the CARPATCLIM dataset (Birsan et al., 2014; Spinoni et al., 2015; Kis et al., 2017) noting that in the work of Kis et al., 2017, the change of precipitation related climatic conditions has been also assessed, but based on simulations of the aforementioned ENSEMBLES project.

Detailed evaluation of EURO-CORDEX and Med-CORDEX RCM simulations driven by the ERA-Interim reanalysis is presented at both resolutions (medium and high) over the Carpathian Region. In total, nine RCM simulations were validated over the region of interest against the CARPATCLIM high resolution gridded observational database. Noting that the relatively high resolution $\left(0.25^{\circ}\right)$ E-OBS observational database (Haylock et al., 2008) is also available encompassing the Carpathians and can serve as reference data (Torma et al., 2011; Szépszó et al., 2014). Considering that CARPATCLIM provides higher station density (compared to E-OBS), data homogenization, and data quality control, this dataset is ideal for validation studies and appropriate reference data for bias correction over the Carpathian Region.

The paper shows the performance of the members of RCM ensembles (EUROand Med-CORDEX) in representing the basic spatiotemporal patterns of the climatic conditions over the Carpathian Region for the period of 1989-2008. The present study aims to evaluate the near-surface minimum, maximum, and mean air temperature (hereafter referred as tasmin, tasmax, and tas, or temperature, respectively) and precipitation on a European regional scale at different time scales. Furthermore, following previous investigations focusing on RCM performance over regions with complex topography (Frei et al., 2003; Kotlarski et al., 2010; Torma et al., 2015; Giorgi et al., 2016), meteorological variables are assessed over a selected sub-region with a relative high average altitude within the Carpathian Region. 
However, it is not the main purpose of the present work to demonstrate the added value of high resolution climate modeling, basic differences between simulations at different resolutions are reported also for the selected mountainous sub-region.
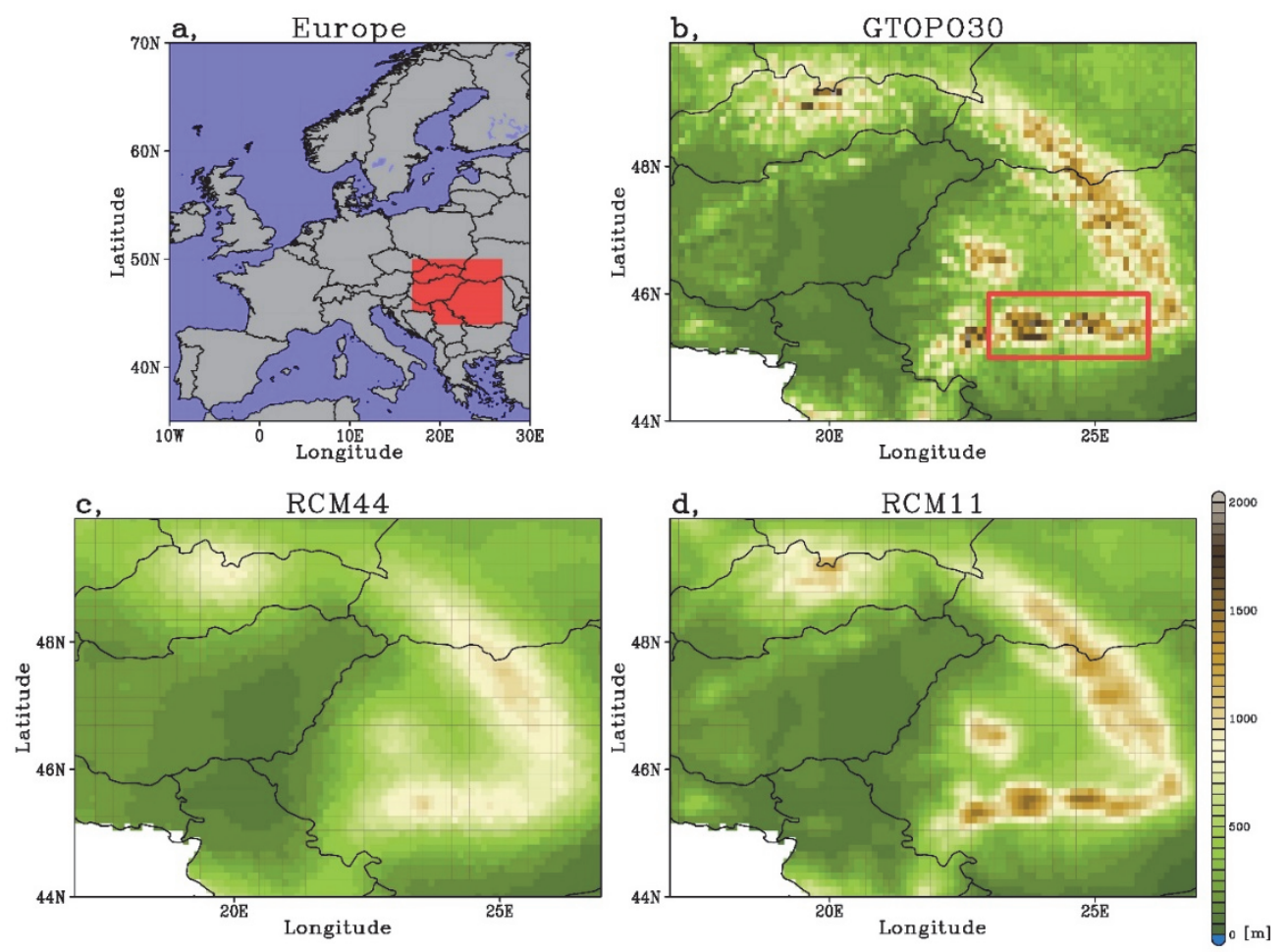

Fig. 1. Analysis regions and topography (on a common $0.11^{\circ}$ grid) over the Carpathian Region. a) Location of the analysis region within the whole European domain (area filled with red color); b) topography based on the GTOPO30 database and the mountainous sub-region used in the analysis (red rectangle); c) average topography of the medium resolution RCMs $\left(0.44^{\circ}\right)$; and d) the average topography of high resolution RCMs $\left(0.44^{\circ}\right)$. Units in b), c), and d) are $\mathrm{m}$. Note that the territory of Bosnia and Herzegovina is not covered by the CARPATCLIM dataset.

In Section 2, the reference observational dataset, the assessed RCM simulations, and the applied re-gridding technique along with the evaluation metrics are introduced. Section 3 provides details of RCMs' performance on reproducing climatic conditions over the Carpathian Region followed by Section 4, in which short summary of the results accompanied with concise considerations are given. 


\section{Data and method}

\subsection{Observation dataset: CARPATCLIM}

The CARPATCLIM dataset provides in total 16 daily meteorological variables (including daily mean, maximum, minimum temperatures and daily precipitation sum) and related derived indicators for the period of 1961-2010 encompassing the Carpathian Region at $0.1^{\circ} \times 0.1^{\circ}$ grid resolution (Szalai et al., 2013). The database is station-based, state-of-the-art quality controlled, covers the Carpathian Mountains and the whole Carpathian Basin (approximately $500000 \mathrm{~km}^{2}$ ), and freely available for scientific purposes through the following link: http://www.carpatclim-eu.org. The technique of Multiple Analysis of Series for Homogenized Database (MASH; Szentimrey and Bihari, 2006) was used for homogenization and data quality control. For interpolation and gridding, the Meteorological Interpolation based on Surface Homogenized Database (MISH; Szentimrey, 2007) method was applied within the CARPATCLIM database. From a network of weather stations covering the Carpathian Region, a number of 415 and 904 stations were used in collecting near surface daily temperature and daily precipitation data, respectively (Spinoni et al., 2015).

One must note that a systematic error related to precipitation measurements is due to the distortion of the wind field above the precipitation gauges. This windinduced undercatch by precipitation gauges can yield an underestimate as of $20 \%$ of actual precipitation, especially over mountainous regions under cold season snowblowing conditions (Adam and Lettenmaier, 2003). Since the CARPATCLIM dataset originally does not account for the wind-induced precipitation undercatch problem, an additional location-dependent monthly gauge undercatch correction was implemented based on the global precipitation dataset of the University of Delaware (UDel Version 3.01; Legates and Willmott, 1990) following the work of Torma et al. (2015). The correction was not applied in the daily precipitation as UDel dataset provides only mean monthly climatological precipitation data.

\subsection{RCM simulations}

All the nine ERA-Interim driven RCM simulations evaluated in this work are reported in detail in Table 1. At the beginning of the present study, from the framework of Med-CORDEX, only three models (ALADIN, RegCM, and PROMES) fulfilled the following requirements: daily precipitation and temperature (mean, minimum, maximum) data are available at both resolutions $\left(0.11^{\circ}\right.$ with a corresponding partner at $0.44^{\circ}$ using identical model version). Whilst EURO-CORDEX could provide six RCMs (CCLM, HIRHAM, RCA, RACMO, REMO, and WRF) fulfilling the aforementioned criteria. Both integration domains (Med-CORDEX and EURO-CORDEX) entirely include the Carpathian Region, and all simulations cover the period of 1989-2008 with LBCs provided by the ERA-Interim reanalysis. 
Table 1: Overview of regional climate models used in the present study. Models provided by the Med-CORDEX framework labeled with an asterisk

\begin{tabular}{|c|c|c|}
\hline Model & Modeling group & Reference \\
\hline ALADIN $5.2^{*}$ & $\begin{array}{l}\text { Centre National de Recherches } \\
\text { Meteorologiques, France }\end{array}$ & Colin et al., (2010) \\
\hline CCLM 4.8.17 & $\begin{array}{l}\text { Climate Limited-area Modelling Community, } \\
\text { Germany }\end{array}$ & Rockel et al., (2008) \\
\hline HIRHAM 5 & Danish Meteorological Institute & Christensen et al., (1998) \\
\hline PROMES* & Universidad de Castilla-La Mancha, Spain & Castro et al., (1993) \\
\hline $\mathrm{RCA} 4$ & $\begin{array}{l}\text { Swedish Meteorological and Hydrological } \\
\text { Institute, Rossby Centre, Sweden }\end{array}$ & Kupiainen et al., (2011) \\
\hline RACMO 2.2 & $\begin{array}{l}\text { Royal Netherlands Meteorological Institute, } \\
\text { The Netherlands }\end{array}$ & Meijgaard et al., (2012) \\
\hline $\operatorname{RegCM} 4.3^{*}$ & $\begin{array}{l}\text { International Centre for Theoretical Physics, } \\
\text { Italy }\end{array}$ & Giorgi et al., (2012) \\
\hline REMO & Climate Service Center, Germany & Jacob et al., (2012) \\
\hline WRF 3.3.1 & $\begin{array}{l}\text { IPSL (Institut Pierre Simon Laplace) and } \\
\text { INERIS (Institut National de l'Environnement } \\
\text { industriel et des RISques), France }\end{array}$ & Skamarock et al., (2008) \\
\hline
\end{tabular}

The ERA-Interim data is a global atmospheric reanalysis produced by the European Centre for Medium-Range Weather Forecasts (ECMWF). ERA-Interim data is available from 1979 (continuously updated once per month) at approximately $80 \mathrm{~km}$ grid resolution and on 60 vertical levels from the surface to $0.1 \mathrm{hPa}$. Analysis fields were constructed in every 6 hours using a variety of observations, the 4D-Var data assimilation technique, and the version of the ECMWF global model which was operational in 2009. The forcing fields provided by the ERA-Interim for the assessed RCMs include not only atmospheric LBCs, but also sea ice cover and sea surface temperature values.

The EURO-CORDEX simulations are integrated over whole Europe, while Med-CORDEX runs focused more on the Mediterranean region (most of the Scandinavian countries are out of the scope). Additional details of the actual regions of different CORDEX domains can be found on the official CORDEX homepage: http://cordex.org/. The RCM simulations of the different model horizontal grid resolutions of $0.11^{\circ}$ and $0.44^{\circ}$ are hereafter referred as RCM11 and RCM44, respectively. Keep in mind, that the main purpose of including simulations from both original resolutions is to give a general comparative overview of those performance over the region of interest. 


\subsection{Regridding}

Since the RCMs and observational datasets do not share the same horizontal grid, according to a previous assessment with a special focus on added value over region with complex topography (Torma et al., 2015), all simulation data (RCM44 and RCM11) and observational data were interpolated onto a common grid spacing of $0.11^{\circ}$. The interpolation was performed by using the Climate Data Operators software (CDO, https://code.mpimet.mpg.de/projects/cdo). The distance-weighted average remapping method was used during the interpolation processes. Though several different interpolation methods are available in the framework of CDO, such as distance weighted, bicubic, bilinear, and field conserving, the distance-weighted method was found to be the most spatial pattern consistent between different resolutions (Torma et al., 2015). Hereafter, all data were evaluated on the common $0.11^{\circ}$ grid. Keep in mind, that the main goal of present work is to give comprehensive information on the performances of RCMs in simulating climatic conditions in different aspects, and it is not primary intention to investigate and reveal the possible added value of high resolution computing.

\subsection{Evaluation metrics}

Different metrics can be used in order to represent the performance of climate models in simulating climatic conditions (Zhao et al., 2013). Besides computing the mean bias and root mean square error (RMSE), the degree of statistical similarity between two climatic fields can be concisely quantified in the form of normalized Taylor diagrams. The diagram, which was originally introduced by Taylor (2001), can be considered as the combination of different measures such as the centered (or bias removed) RMSE, spatial standard deviation (STDV), and spatial correlation. Geometric relationship between these metrics allows that the performance of each model in comparison to CARPATCLIM (serving as reference) can be displayed on the same diagram. The azimuthal position of a symbol in the Taylor diagram gives information on the spatial correlation coefficient between the RCM results and the reference. The radial distances from the origin to each symbol are proportional to the pattern standard deviation normalized by the reference variance, thus reference located at value 1 . The distances of each symbol (along concentric circles) from this reference point indicate the centered RMSE based on the RCM and reference data. Note that the centered RMSE values were also standardized with the variance of the reference data. Consequently, symbols representing the best performing RCMs are positioned closest to this reference point. The Taylor diagrams reported in the present study are based on 20-year seasonal means in grid points, except for the assessed climate indices, where 20year annual means in each grid point were used. 
The spatial distribution of mean precipitation, the annual cycle of mean monthly precipitation along with the mean monthly temperature bias averaged over the entire analysis region, as well as the probability distribution function (PDF) of daily precipitation events are also presented in this work. In order to assess the model performances in simulating different characteristics of daily precipitation and temperature, four hydrological and thermal indices are evaluated. The following four precipitation and temperature related climate indices (Karl et al., 1999; Peterson et al., 2001) recommended by the Expert Team in Climate Detection and Indices (ETCCDI) have been examined:

- SU: number of summer days (days with maximum temperature $>25{ }^{\circ} \mathrm{C}$ )

- FD: number of frost days (days with minimum temperature $<0{ }^{\circ} \mathrm{C}$ )

- CDD: consecutive dry days (number of periods with precipitation $<1 \mathrm{~mm} /$ day over at least 5 days)

- R95: fraction of precipitation accounted for by events above the 95th percentile (R95 is computed using all days rather than only days with precipitation $>1 \mathrm{~mm}$ )

Note that R95 is relative to a given PDF and is not a measure of absolute extremes, but it is also commonly used in analyzing of extremes (Sillmann et al., 2013; Giorgi et al., 2016).

\section{Evaluation of RCM data}

\subsection{Mean precipitation and temperature characteristics}

Before turning our attention to daily precipitation and temperature statistics, it is also important to provide an evaluation of the model performances on simulating the mean precipitation and temperature characteristics throughout the year over the region of interest (Fig. Ia). Fig. 2 represents the annual cycle of monthly precipitation averaged over the Carpathian Region. Information depicted in Fig. 2 is derived from the ERA-Interim database and from the RCM44 and RCM11 simulations, the CARPATCLIM is also depicted with and without the gaugecorrection on the common $0.11^{\circ}$ grid. The Carpathian Region experiences a precipitation maximum in summer (June, July) and a minimum in winter (December, January). In general, the RCM ensembles reproduce the annual cycle with a more pronounced precipitation maximum in June. It is also interesting that RCM11 simulations basically give more abundant precipitation during the whole year compared to RCM44 simulations, with the largest extent between May and August, when most of the convective processes occur within the region of interest. Following this, the enhanced precipitation can be attributed to an increase of convective rainfall due to topographical modulation (Giorgi et al., 2016). Such phenomenon is expected to be better represented by simulations where orography is described at higher resolutions (Torma et al., 2015). Both RCM ensembles 
generally underestimate the precipitation throughout a relatively warm period between July and September. During spring, precipitation is overestimated (March, April, May), especially by RCM11, even compared to the corrected observations. It can be seen that during October-November-December, the simulated precipitation is more in line with the corresponding field in ERAInterim than with the observations (CARPATCLIM). One might also notice in Fig. 2, that the spread of RCM simulations does not decrease with higher grid resolution. This fact can be attributed to different factors such as the increased surface internal variability on small scales due to the topographic forcing and locally strong surface heterogeneities at higher resolutions (Separovic et al., 2008), or the amplification of biases already present in the boundary conditions (Laprise et al., 2008). But it is also important to keep in mind, that higher resolution RCM simulations are expected to provide more accurate frequency distributions of daily weather events and extremes rather than decreasing mean bias fields (Giorgi 2006; Laprise et al., 2008; Torma et al., 2015).

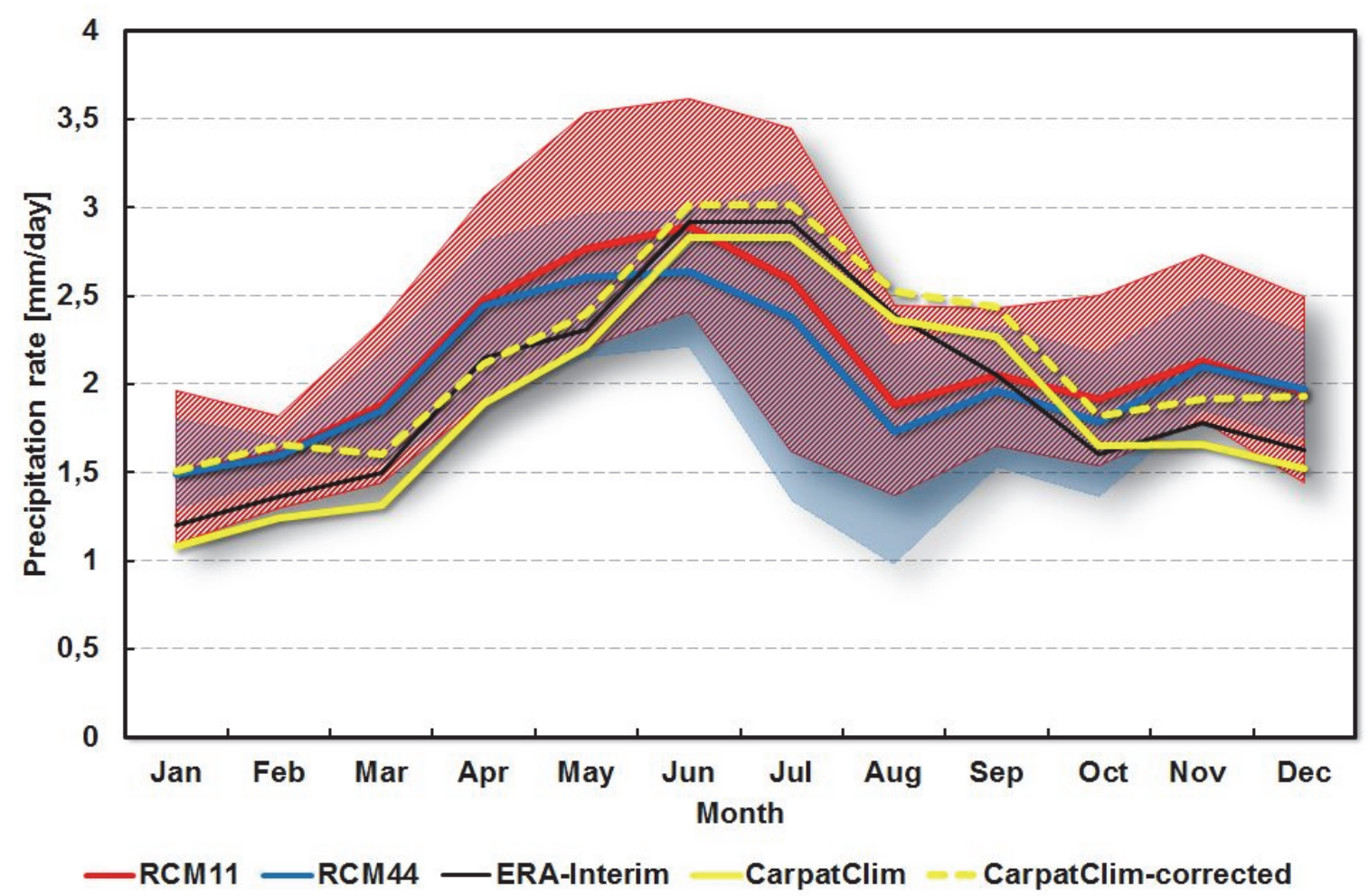

Fig. 2. Monthly mean precipitation averaged over the Carpathian Region for the reference period of 1989-2008 for the ERA-Interim (black), CARPATCLIM (yellow, dashed line stands for the gauge-corrected version), and RCM simulations (ensemble mean of RCM11 with red, ensemble mean of RCM44 with blue). Units are $\mathrm{mm} /$ day. 
Fig. 3 shows the spatial distribution of mean winter (December-JanuaryFebruary, or DJF), spring (March-April-May, or MAM), summer (June-JulyAugust, or JJA), and autumn (September-October-November, or SON) precipitation for the ensemble average of RCM44 and RCM11 along with the corresponding field in ERA-Interim and CARPATCLIM with and without the gauge correction, all interpolated onto the common $0.11^{\circ}$ grid. In general, regardless of the original resolution, $\mathrm{RCMs}^{\prime}$ performance in representing seasonal mean precipitation over the Carpathian Region reflects in cold and warm seasonal dependencies. More specifically, DJF precipitation is slightly overestimated by about $5 \%$ by HIRHAM, RCA, and WRF, and exaggeratedly by $\mathrm{RegCM}(20 \%)$. While, in general, all RCMs underestimate JJA precipitation $(\sim 0 \%-20 \%)$, except for PROMES $(\sim+15 \%)$. It is worth mentioning that the model REMO underestimates seasonal precipitation for all seasons with an average of $15 \%$. It can be seen that higher resolution comes with an increase in precipitation detail, which phenomenon can be attributed to the topographical features of the Carpathians (Fig. 1), and it had been reported over different regions all over Europe in the work of Fantini et al. (2016). Analyzing the spatial distributions of seasonal precipitation fields it is evident, that in all seasons the precipitation maxima are mostly topographically induced. The precipitation maxima are found across the western flanks of the northern Carpathians in the observations throughout all the four seasons (DJF, MAM, JJA, SON) with higher values in RCM11 simulations over the southern peaks of the Carpathians. It is also evident, that the effect of the undercatch correction is more prominent in the cold season (DJF) over regions with high elevations. 

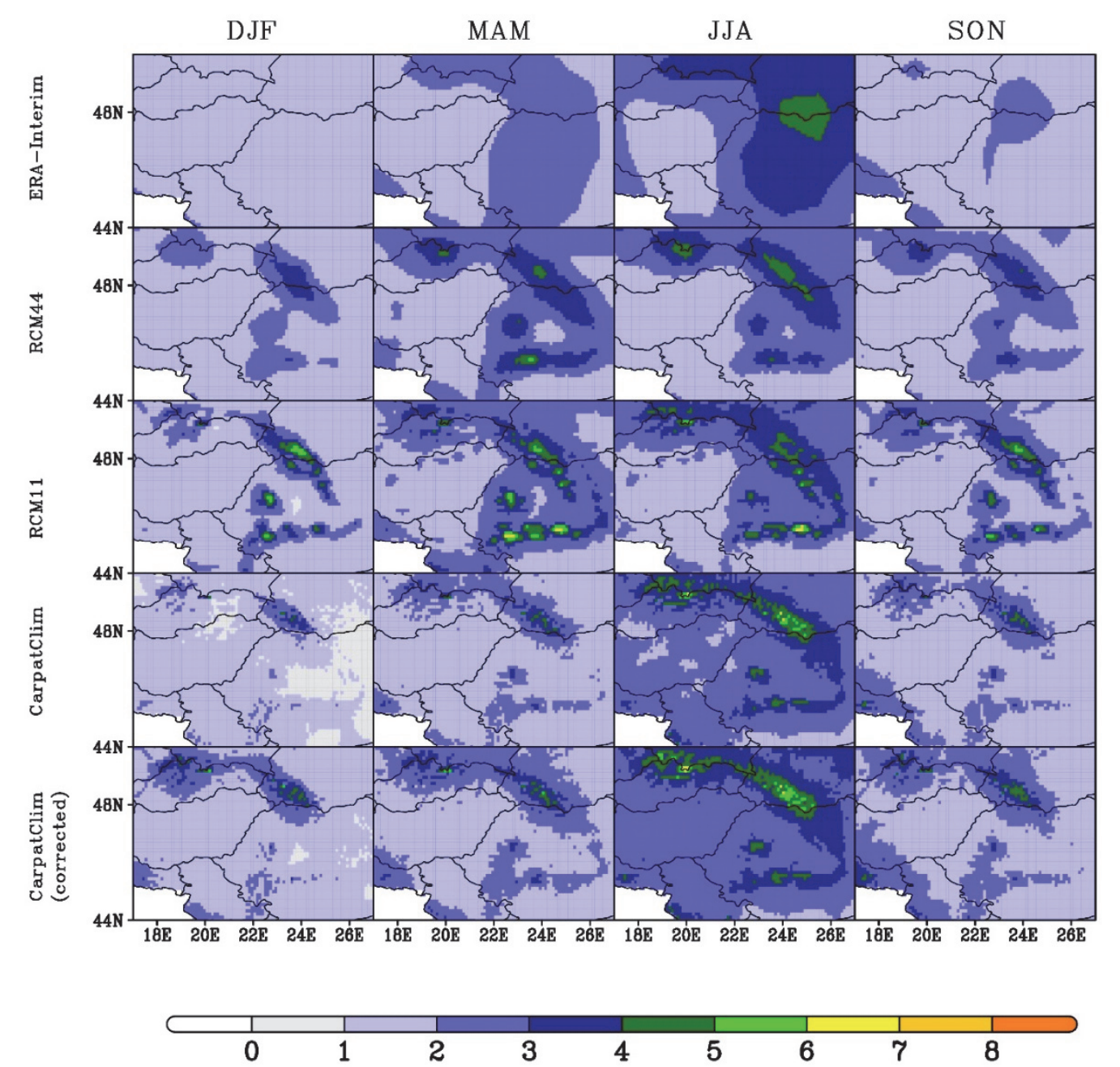

Fig. 3. Mean (1989-2008) winter (December-January-February, DJF), spring (March-April-May, MAM), summer (June-July-August, JJA) and autumn (September-October-November, SON) precipitation for the ERA-Interim (top row) reanalyses, the ensembles of RCM44 and RCM11 (second and third row, respectively) simulations, and the CARPATCLIM observations without and with undercatch gauge correction (last two rows). Units are $\mathrm{mm} /$ day.

The centered RMSE along with the STDV and the spatial correlations of RCM44 and RCM11 simulations against CARPATCLIM dataset assessed over the Carpathian Region for the period of 1989-2008 in Fig. 4. The Taylor diagrams enable a direct comparison of different (in sense of resolution and physics) RCM simulations on a common grid $\left(0.11^{\circ}\right)$. In the Taylor diagrams, the high resolution RCM11 simulations are depicted with open circles, while the medium resolution RCM44 simulations are indicated with closed circles. In addition, in Fig. 4, the gauge-corrected CARPATCLIM was used as reference data, since this corrected data is more likely to be representative in sense of mean precipitation climatology over mountainous regions (Torma et al., 2015; Fantini et al., 2018). Also note that the 
application of such correction on the observations does not alter significantly the assessed performance metrics (i.e., correlation; Torma et al., 2015). During the four seasons, the group of RCM44 simulations is not sharply separated from the RCM11 simulations in general. The biggest uncertainty in representing seasonal mean precipitation over the Carpathian Region occurs in MAM, while relatively the smallest centered RMSE and the highest spatial correlation values can be found in JJA. In DJF (when precipitation shows minimum), the spread of the RCM simulations is relatively small, but at the same time, their performance on simulating the spatial distribution of precipitation is also poor in general. Based on the Taylor diagrams for all four seasons, among the best performing RCMs are as follows: ALADIN, RACMO, and CCLM. In particular RACMO (RCM11) shows the highest spatial pattern correlations, while exhibits one of the best scores in terms of normalized STDV and centered RMSE. Whilst HIRHAM model can be considered as an outlier, as it exhibits qualitatively modest performances regardless of the season. Specifically, it can be seen in case of HIRHAM (RCM44) that large spatial variability (standard deviation ratio generally exceeds 1.5 , in season MAM even 2.5) comes along with the largest centered RMSE in all seasons.
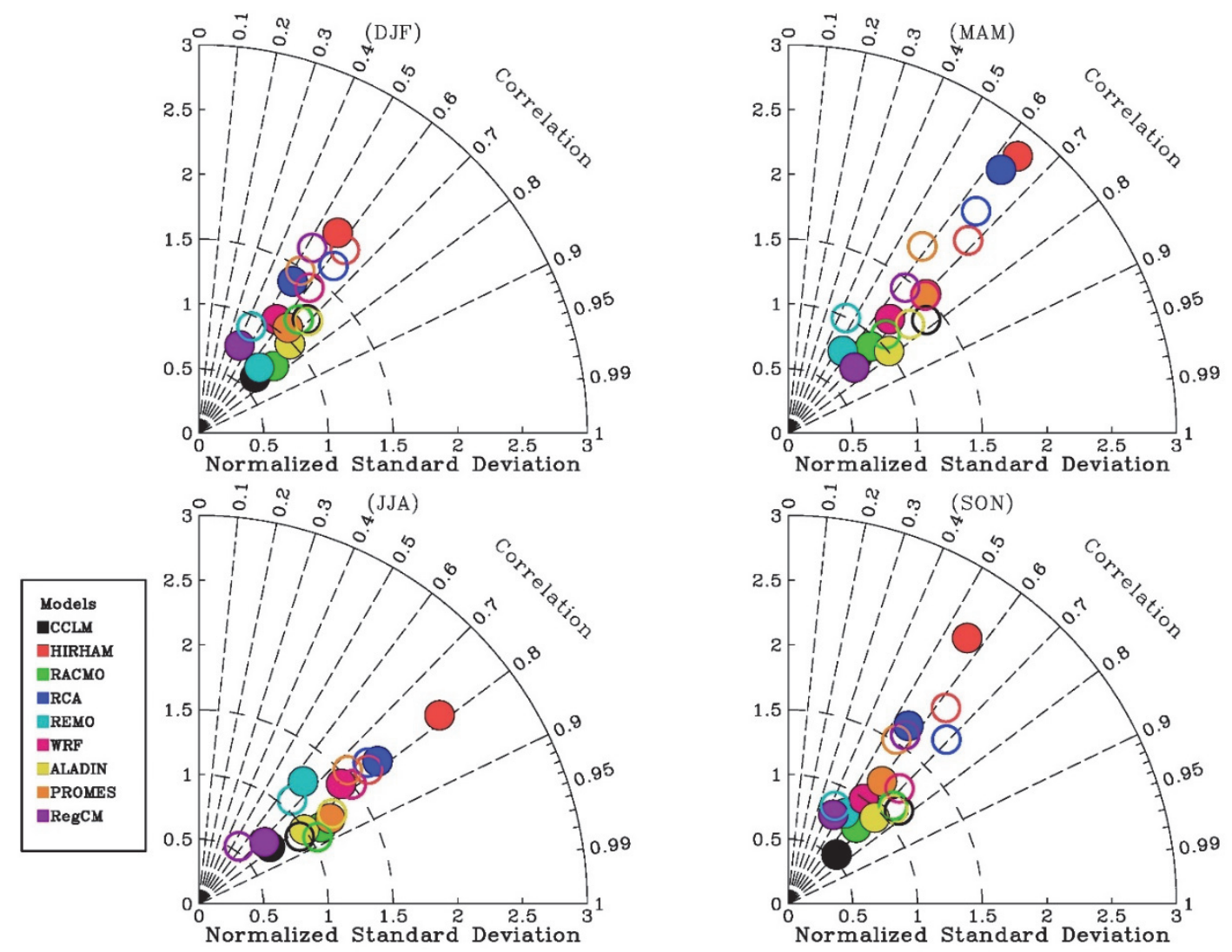

Fig. 4. Taylor diagram of mean (1989-2008) seasonal precipitation for the two model ensembles (filled circles for the RCM44, open circles for the RCM11) versus the gauge-corrected CARPATCLIM observations. The four panels refer to the four seasons (DJF, MAM, JJA, and SON). 
In order to reveal more in depth the capacity of RCMs in reproducing climatic conditions over the Carpathian Region, further assessments of additional variables are needed. For this purpose the mean seasonal temperature fields and the annual cycle of mean temperature bias fields averaged over the region of interest for the reference period 1989-2008 are reported in Figs. 5 and 6, respectively. Fig. 5, following the concept of Fig. 3, demonstrates the spatial features of temperature simulations, along with the ERA-Interim and the observations. It must be noticed, that moving towards the originally higher resolution information, the finer the details are in the spatial distribution of the seasonal temperature fields. The Carpathian Mountains play an evident role in the formation of seasonal temperature fields in the Carpathian Region. In all seasons, the peaks of the Carpathians excel with their relatively lower temperature compared to their surroundings. Even the highest peak within the Carpathian Region (Gerlachov Peak, located in Slovakia) can be recognized based on the mean seasonal temperature fields (i.e., MAM and $\mathrm{SON}$ ) derived from the RCM11 simulations. Additionally, the spatial features of mean seasonal temperature fields of RCM11 simulations even reveal the ranges of Apuseni Mountains (mountain range in Transylvania), which is in fact is valid for all seasons, but not for the RCM44 simulations.

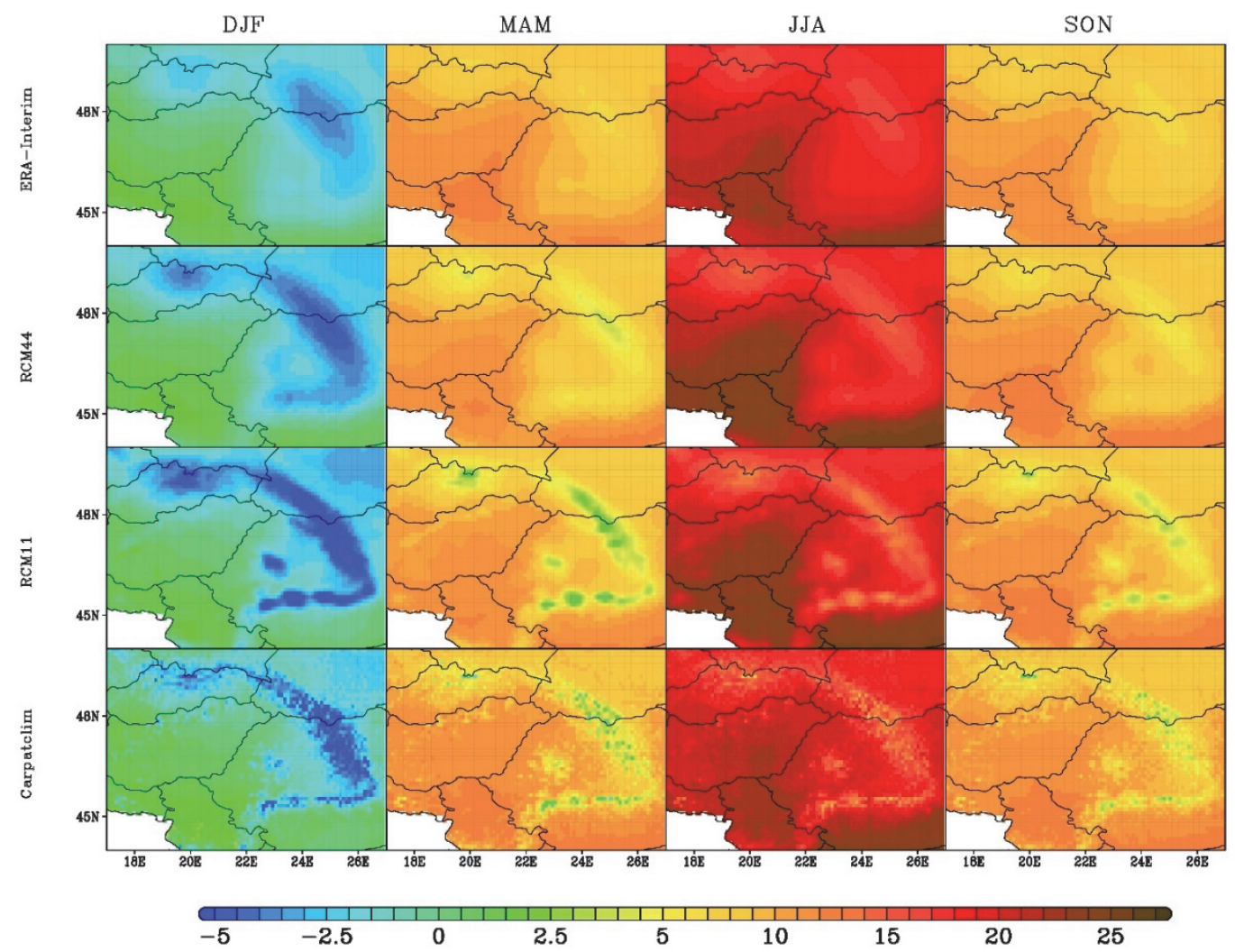

Fig. 5. Mean (1989-2008) winter (December-January-February, DJF), spring (MarchApril-May, MAM), summer (June-July-August, JJA), and autumn (SeptemberOctober-November, SON) temperature for the ERA-Interim (top row) reanalyses, the ensembles of RCM44, and RCM11 (second and third row, respectively) simulations, and the CARPATCLIM observations (last row). Units are ${ }^{\circ} \mathrm{C}$. 


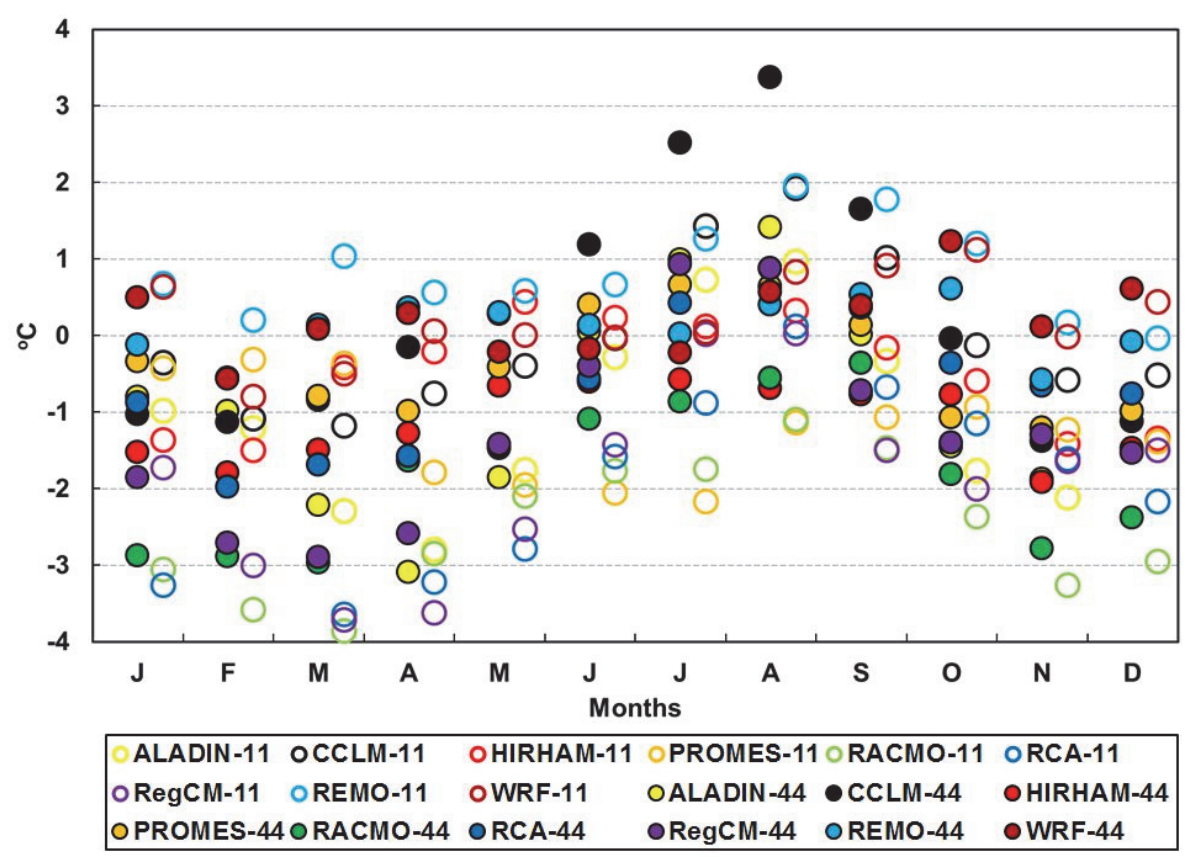

Fig. 6. Monthly mean temperature bias averaged over the Carpathian Region for the reference period of 1989-2008. RCM44 marked with closed circles, while $\mathrm{RCM} 11$ are depicted by open circles. Units are ${ }^{\circ} \mathrm{C}$.

Again, higher resolution RCM simulations are not expected to decrease the mean bias fields (as referred in the previous section), and actually the standard deviation of bias averaged over the Carpathian Region in each month is larger in case of RCM11 compared to the RCM44 ensemble (Fig. 6). The wide range of the spread in monthly biases can be directly attributed to the different topography and parameterizations implemented in the evaluated RCM simulations. Fig. 6 also shows a strong time dependency, as temperature biases are not constant in time. They have a clear annual cycle: there is no RCM with a constant positive or negative temperature bias through the year, temperature is generally overestimated in August, whilst underestimated to a varying extent in the rest of the year. One might also notice, that RCM11 simulations do not always show better performance in simulating cold or warm climatic conditions compared to their partner RCM44 simulations. The spread of bias fields mostly ranges between $-3{ }^{\circ} \mathrm{C}$ and $+3{ }^{\circ} \mathrm{C}$, only ALADIN, RegCM, RACMO, RCA (underestimation), and CCLM (overestimation) models are slightly exceeding these limits. RegCM and RACMO typically show a strong cold bias when compared to the CARPATCLIM observational dataset. In general, WRF performs among the best RCMs (median is -0.1 for RCM11 and 0.2 for RCM44): i.e., producing close to zero mean bias during the period of April-May-June-July. 
Further assessments are accomplished over a selected sub-region in the Carpathian Region to investigate the benefits of high resolution computing over complex topography. The mountainous sub-region with high mean elevations is highlighted with red box in Fig. $1 \mathrm{~b}$. All the aforementioned four meteorological variables (pre, tas, tasmin, and tasmax) are evaluated against the CARPATCLIM dataset over this sub-region in the form of Taylor diagram and reported in Fig. 7 (closed circles represent the RCM44, and open circles are for the RCM11 simulations) for JJA during 1989-2008. As referred previously, higher resolution simulations have the potential to describe more accurately the frequency distributions of daily weather events and extremes, especially over regions with complex topography, when grid resolutions do really matter (Giorgi, 2006; Laprise et al., 2008; Torma et al., 2015). Over the mountainous sub-region, higher resolution RCM simulations lead to a slightly improved representation of precipitation, which manifested in higher spatial correlations. RCM11 simulations compared to their RCM44 pairs show increased STDV values, furthermore, all RCM11 simulations overestimate the STDV by exceeding 1 as representative for the reference. During the analyzed period (JJA), when the precipitation maximum occurs, the model REMO realized the poorest performance. At both resolutions, REMO shows displacement of maximum values over the southern ridges of the Carpathians. Moreover, in contrast with observations, a peak with minimum precipitation also appears within the selected sub-region (not shown). Low spatial correlation values (RCM44 REMO exhibits negative correlation) are clear consequences of the aforementioned facts. While in case of precipitation, symbols of RCM44 and RCM11 simulations still overlapping each other, but for temperature (tas, tasmin, and tasmax) evident clusters of RCM44 and RCM11 simulations can be seen, and RCM11 simulations obviously outperform their RCM44 pairs. This can be seen in the improved values of centered RMSE, STDV, and spatial correlations as well. Nevertheless, in the RCM11 simulations, tasmax values are better represented over the selected sub-region than tasmin, as for tasmin they show too high spatial variability. In other seasons similar performances were found (not shown for brevity). It is worth mentioning that CCLM and RACMO models are among the best performing models, which is in line with the previous findings published in the work of Kotlarski et al. (2017). 

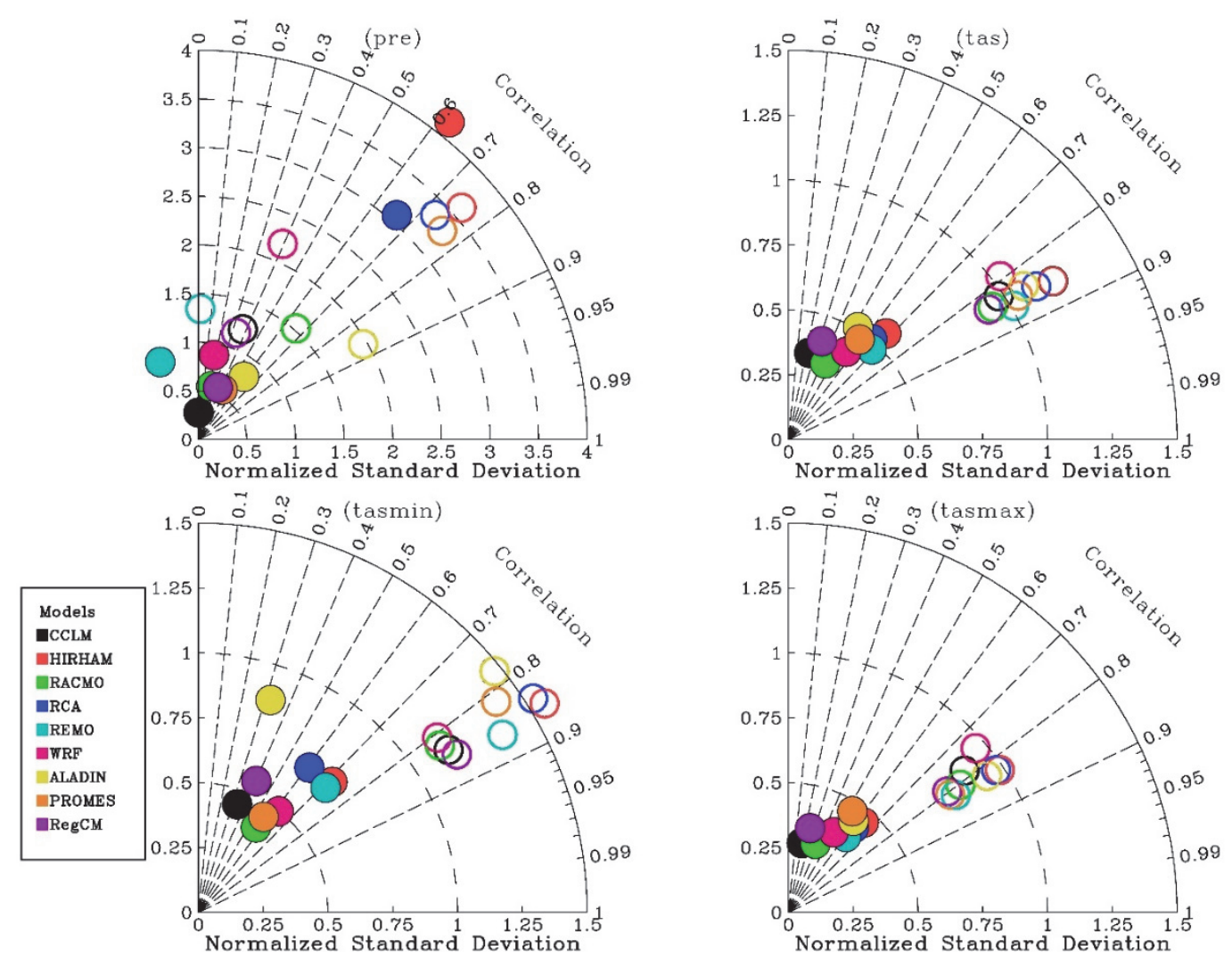

Fig. 7. Taylor diagram of precipitation (pre), temperature (tas), minimum temperature (tasmin), and maximum temperature (tasmax) (closed circles for the RCM44, open circles for RCM11 simulations) versus the CARPATCLIM observations (the gauge-corrected observations in case of precipitation) over the mountainous region for JJA in the period of 1989-2008.

\subsection{Climate indices}

In order to investigate the daily precipitation intensities, Fig. 8 presents the PDFs of all daily precipitation during the period of 1989-2008 from RCM11 and RCM44 ensembles. All data were interpolated onto the $0.11^{\circ}$ resolution grid of the Carpathian Region along with the corresponding observational dataset. On average, the RCM simulations appear to be consistent with the low-intensity tail of observed distribution (up to about $50 \mathrm{~mm} /$ day), but mostly overestimate the frequency of the high-intensity events (exceeding $100 \mathrm{~mm}$ /day), especially RCM11. PDFs derived from RCM44 simulations are more in line with observations than their higher resolution partners, which is in fact the opposite what was found for another European regions with complex topography (Torma et al., 2015). There are different possible explanations for this finding. On the one hand, these results can be attributed to the fact that RCMs can simulate unrealistic high precipitation intensities at high grid resolutions over different regions (i.e., due to the sensitivity of the implemented convective parameterization). On the other hand, these results 
might reveal some deficiencies of the CARPATCLIM reference dataset, as the effective resolution might be lower than the nominal $0.1^{\circ}$ over regions of low station network density (Fantini et al., 2016; Kotlarski et al., 2017). As a direct consequence of this, CARPATCLIM dataset might underrepresent the frequency of the events with high precipitation over those regions. Both explanations turn attention to exciting challenges arise in regional climate modeling.

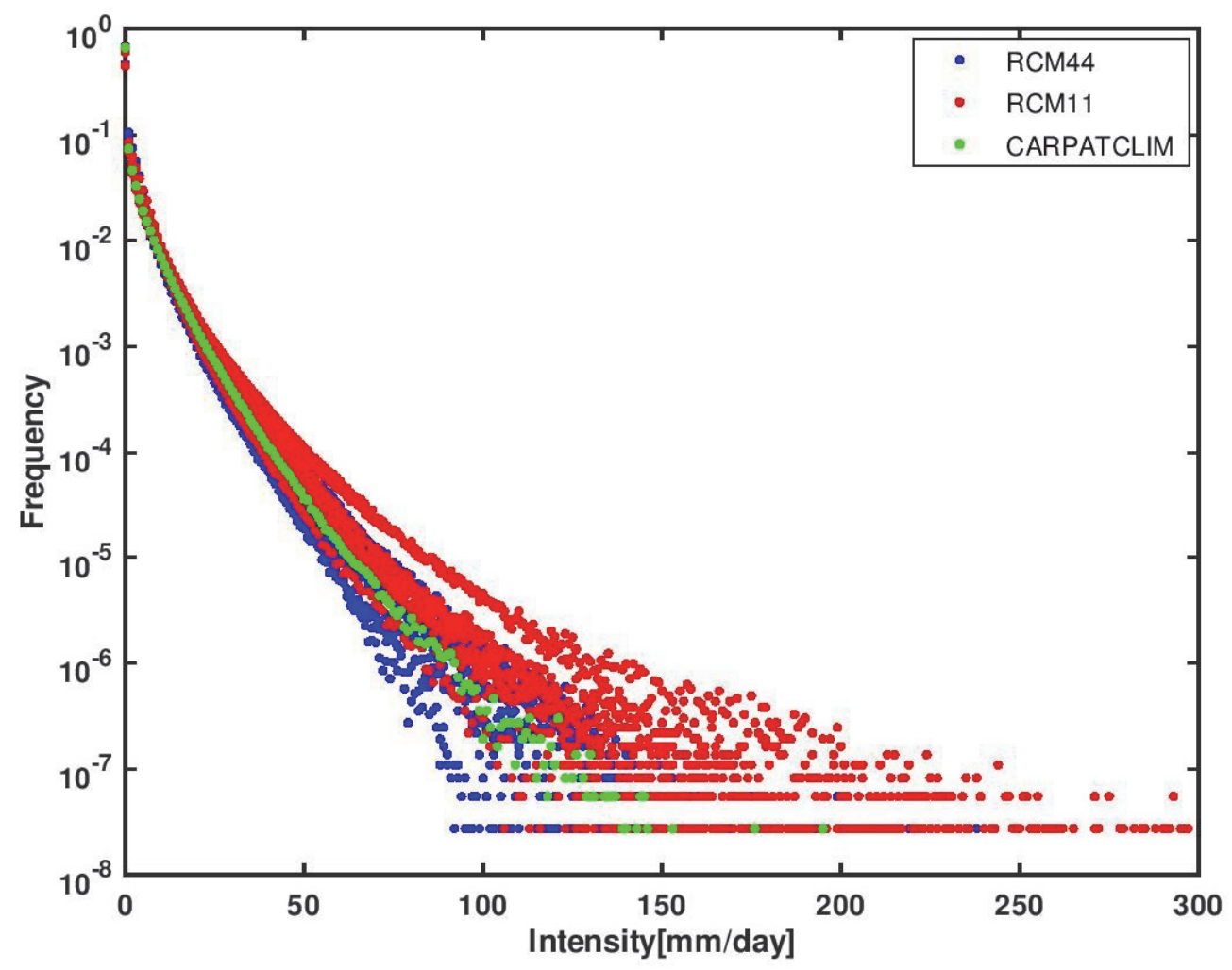

Fig. 8. Daily precipitation intensity empirical probability distribution functions (PDFs) (frequency versus intensity of daily precipitation events for the period of 1989-2008) for RCM44 (blue) and RCM11 (red) model experiments, and the CARPATCLIM observations (green).

Fig. 9 shows the spatial distribution of R95 for the RCM44 and RCM11 ensemble means with the corresponding observations. The R95 metric was defined in Section 2.4 and is calculated including all days with no additional restrictions in the reference period (1989-2008). The observed values of R95 at the common $0.11^{\circ}$ resolution grid vary mostly in the range of $24-38 \%$, with some higher peaks in the southern-southeastern part of the Carpathians and over a smaller region in the western part of the Carpathian Region. Sharp contrast can also be noticed between the western/eastern and northern/southern sides of the Carpathians, while R95 has generally lower values on the west, but higher values 
on the east, and shows more prominent maximum over the southern part of the southern range of the Carpathians. This contrast can be found in both RCM ensembles, but only RCM11 ensemble presents the two aforementioned regions with high R95 values. By and large, RCM44 ensemble can capture well the locations of R95 maxima and minima, but typically underestimates them and misses the high resolution details with the corresponding locations of maxima, indicating the benefits of using higher resolution information in the assessment of R95.
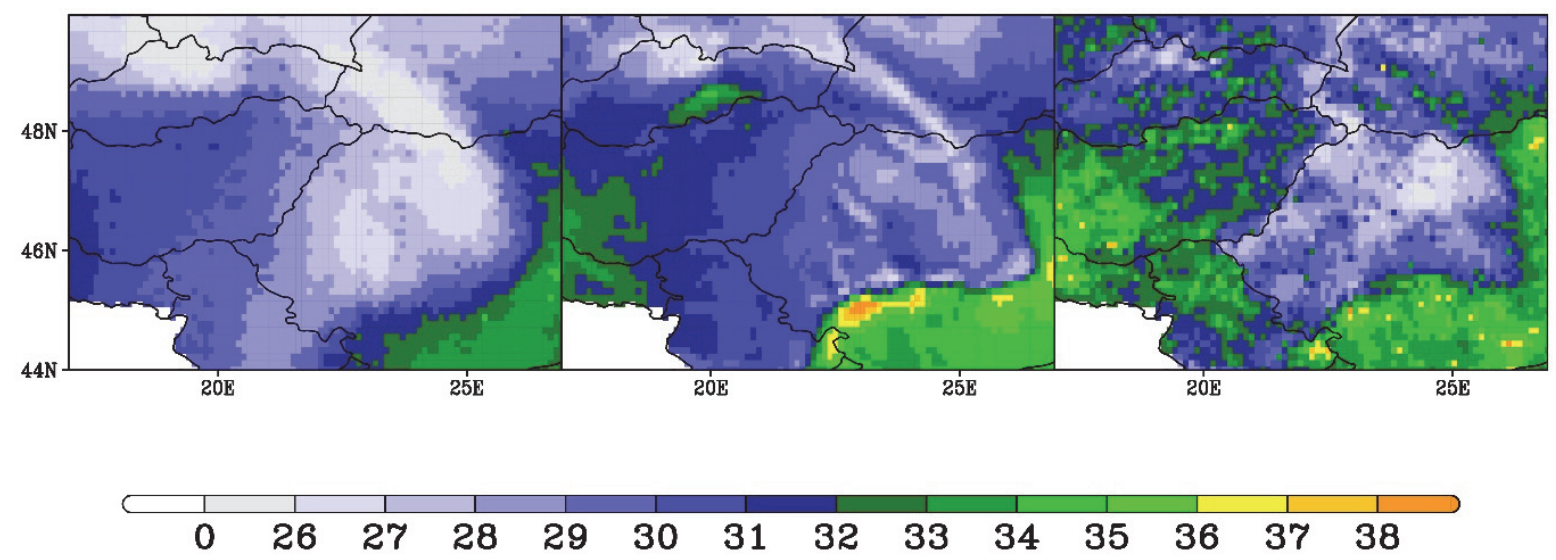

Fig. 9. Ensemble mean of R95 index for the RCM ensembles (RCM44 on the left panel, RCM11 on the middle panel) and the CARPATCLIM observations (right panel) for the period of 1989-2008. Units are in percent of total precipitation accounted for by events above the 95 th percentile.

Fig. 10 summarizes the performances of individual RCM11 and RCM44 simulations against the CARPATCLIM observational dataset in representing the CDD, R95, FD, and SU climate indices over the mountainous sub-region within the Carpathian Region. Taylor diagrams for CDD and R95 demonstrate that simulation of days with low or no precipitation can be quite challenging over regions with complex topography for the RCMs. In case of the CDD, regardless the RCM, higher resolution typically manifested in higher STDV and spatial correlation values, except for HIRHAM. RCM44 version of REMO shows negative correlation, whereas CCLM and ALADIN results could be considered as the best ones. For R95, RCMs showed better agreement with the reference dataset compared to the CDD. Among RCM11 simulations, CCLM and RACMO models provides remarkably better results, while HIRHAM, PROMES, and RegCM models performed more modestly. From overlap of symbols for RCM44 and RCM11 simulations one can conclude that not all RCM11 members show improvement with respect to the RCM44 members. 

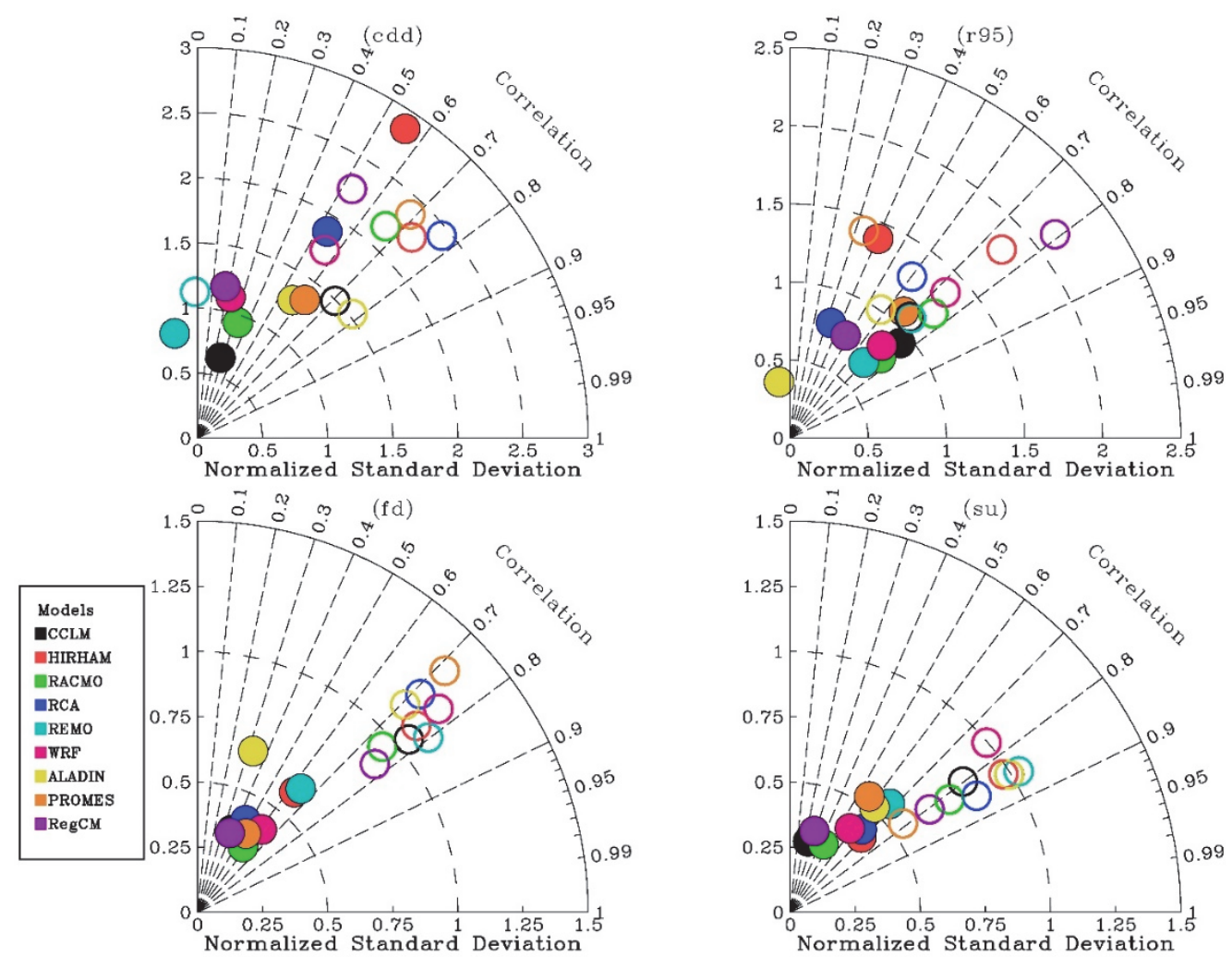

Fig. 10. Same as Fig. 7, but for annual values of climate indices CDD (top left), R95 (top right), FD (bottom left), and SU (bottom right). Note that no additional gauge-correction was implemented on daily observational data.

In general, RCMs perform better in reproducing thermal climatic conditions than simulating precipitation events. This can be attributed to the fact that precipitation shows higher variability in space and time than temperature, thus it is more challenging to be simulated by RCMs. For FD and SU, a clear separation of RCM44 and RCM11 ensemble members can be seen. RCM11 versions of CCLM, RACMO, and REMO simulate FD with good agreement over the subregion. As member of the same ensemble, PROMES showed weaker results for both temperature indices. In case of the SU index, the high resolution simulations of HIRHAM, ALADIN, and REMO provided the most reasonable results (noting that in other aspects as showed earlier, HIRHAM was considered as an outlier). These findings can support the fact that higher resolution RCM simulations can give more valuable information on extremes and climate indices than coarser ones. All the results reported in the present study demonstrate the lack of a single model above all other models. 


\section{Summary and final considerations}

In the present study, nine RCMs as members of the European branches of CORDEX (EURO- and Med-CORDEX) have been evaluated over a 20-year long reference period (1989-2008) against the high-resolution, gridded CARPATCLIM observational dataset. Overarching aim of the present study is to provide useful information on general capabilities of given RCMs in reproducing climatic conditions over the Carpathian Region. All RCM simulations provided daily precipitation and temperature (tas, tasmin, and tasmax) data at both nominal resolutions of $0.11^{\circ}$ and $0.44^{\circ}$, and have been evaluated on a common $0.11^{\circ}$ grid against the CARPATCLIM dataset.

By and large, the annual precipitation cycle averaged over the Carpathian Region is well represented by both RCM44 and RCM11 ensembles. According to the spatial distribution of seasonal precipitation, RCM11 generally produced a more pronounced precipitation maxima over the southern peaks of the Carpathians compared to RCM44. ALADIN, CCLM, and RACMO exhibited good results, while HIRHAM showed relatively poor performances in simulating mean precipitation fields regardless of the season. The average temperature bias values range between $-3{ }^{\circ} \mathrm{C}$ and $+3{ }^{\circ} \mathrm{C}$. WRF (RCM11) could be considered as one of the best performing RCMs, while for among others, RegCM, and RCA showed strong cold bias through the year in the analyzed period. Over a selected sub-region described as region with high mean elevation, RACMO and CCLM provided the best agreement with the CARPATCLIM dataset for JJA in all aspects (pre, tas, tasmin, and tasmax). Further climate indices (FD, SU, CDD, and R95) were computed and assessed over the entire region of interest and over the subregion as well. In general, in case of the temperature related climate indices (FD and SU), RCM11 ensemble showed better agreement with observations than RCM44 ensemble. For FD and SU climate indices, PROMES model showed relatively poor performance. While the models ALADIN, HIRHAM, and REMO were found to be the best in representing FD and SU over the selected sub-region, respectively. In general, CCLM represented remarkably good performances for CDD and R95, while HIRHAM is found to show modest results.

According to the findings reported in the present work, the following considerations can be made: (1) there is not a single RCM outperforming the other ones in all aspects, but it is also important to note that all RCMs have their strength and weaknesses; (2) better description of extremes and climate indices can be achieved by applying higher resolution simulations; (3) due to the amplification of biases already present in the BCs or the increased internal variability on small scales induced by strong local surface heterogeneities within the regional domain, higher resolution RCM simulations not necessarily reduce the uncertainties; (4) RCM performances are also influenced by observational uncertainties. On the one hand, observational uncertainties might be high over regions with relatively sparse station network, especially over regions with high elevations (Prein and Gobiet, 
2017). On the other hand, the ever increasing resolution of current state-of-the-art RCMs constantly requires and highlights the need of quality controlled, high resolution observational datasets for their assessment and development. Such comprehensive evaluations discussed in the present study cannot be done on a continental scale (i.e., over entire Europe), only over sub-regions covered by highquality, high resolution observational datasets such as the CARPATCLIM. This statement draws attention to the fact, that there is still an urgent need in integrating such observational datasets over the entire European continent.

Acknowledgements: The research leading to these results has received funding from the Hungarian Academy of Sciences under the Premium Post-Doctoral Research Program. All data from EUROCORDEX and Med-CORDEX modeling groups used in this work and CARPATCLIM, Database $\mathbb{C}$ European Commission - JRC 2013, along with GTOPO30 data provided by the U.S. Geological Survey are acknowledged. The data used in this work can be found at the following web sites: http://cordexesg.dmi.dk/esgf-web-fe/ (EURO-CORDEX), http://www.medcordex.eu/medcordex.php (Med-CORDEX), http://www.carpatclim-eu.org/pages/download/ (CARPATCLIM), and https://www.esrl.noaa.gov/psd/data/gridded/data.UDel_AirT_Precip.html (UDel). The author is also grateful to the anonymous reviewer for thorough revision of the manuscript, which helped to significantly improve the quality of the paper.

\section{References}

Adam, J.C. and Lettenmaier, D.P., 2003: Adjustment of global gridded precipitation for systematic bias. J. Geophys. Res. 108(D9), 4257. https://doi.org/10.1029/2002JD002499

Beniston, M., Stephenson, D.B., Christensen, O.B., Ferro, C.A.T., Frei, C., Goyette, S., Halsnaes, K., Holt, T., Jylhä, K., Koffi, B., Palutikof, J., Schöll, R., Semmler, T., and Woth, K., 2007: Future extreme events in European climate: An exploration of regional climate model projections. Climat. Change 81 S1, 71-95. https://doi.org/10.1007/s10584-006-9226-z

Birsan, M.-V., Dumitrescu, A., Micu, D.M., and Cheval, S., 2014: Changes in annual temperature extremes in the Carpathians since AD 1961. Nat Hazards 74, 1899-1910. https://doi.org/10.1007/s11069-014-1290-5

Castro, M., Fernández, C., and Gaertner M.A., 1993: Description of a mesoscale atmospheric numerical model. In: (eds. Díaz JI, Lions JL) Mathematics, climate and environment. Recherches en Mathematics Appliques Series Mason, 230-253.

Christensen, O.B., Christensen, J.H., Machenhauer, B., and Botzet, M., 1998: Very highresolution regional climate simulations over Scandinavia - Present climate. J Climate 11, 3204-3229. https://doi.org/10.1175/1520-0442(1998)011<3204:VHRRCS $>2.0 . C O ; 2$

Christensen, J.H. and Christensen, O.B., 2007: A summary of the PRUDENCE model projections of changes in European climate by the end of this century. Climatic Change 81 S1,7-30. https://doi.org/10.1007/s10584-006-9210-7

Colin, J., Deque, M., Radu, R., and Somot, S., 2010: Sensitivity study of heavy precipitation in limited area model climate simulations: influence of the size of the domain and the use of the spectral nudging technique. Tellus A 62, 591-604. https://doi.org/10.1111/j.1600-0870.2010.00467.x

Dee, D.P., Uppala, S.M., Simmons, A.J., Berrisford, P., Poli, P., Kobayashi, S., Andrae, U., Balmaseda, M. A., Balsamo, G., Bauer, P., Bechtold, P., Beljaars, A. C. M., van de Berg, L., Bidlot, J., Bormann, N., Delsol, C., Dragani, R., Fuentes, M., Geer, A. J., Haimberger, 
L., Healy, S. B., Hersbach, H., Hólm, E. V., Isaksen, L., Kållberg, P., Köhler, M., Matricardi, M., McNally, A. P., Monge-Sanz, B. M., Morcrette, J.-J., Park, B.-K., Peubey, C., de Rosnay, P., Tavolato, C., Thépaut, J.-N. and Vitart, F., 2011: The ERA-Interim reanalysis: configuration and performance of the data assimilation system. Quart. J.Roy. Meteor. Soc. 137, 553-597. https://doi.org/10.1002/qj.828

Fantini, A., Raffaele, F., Torma, Cs., Bacer, S., Coppola, E., and Giorgi, F., 2018: Assessment of multiple daily precipitation statistics in ERA-Interim driven Med-CORDEX and EURO-CORDEX experiments against high resolution observations. Climat. Dynam. 51, 877-900. https://doi.org/10.1007/s00382-016-3453-4

Frei, C., Christensen, J. H., Déqué, M., Jacob, D., Jones, R. G., and Vidale, P. L., 2003: Daily precipitation statistics in regional climate models: Evaluation and intercomparison for the European Alps. J. Geophys. Res. 108, 4124. https://doi.org/10.1029/2002JD002287

Giorgi, F., 2005: Climate change prediction. Climatic Change 73, 239-265. https://doi.org/10.1007/s10584-005-6857-4

Giorgi, F., 2006: Regional climate modeling: Status and perspectives. J. Phys. IV, 139, 101118. https://doi.org/10.1051/jp4:2006139008

Giorgi, F., Jones, C., and Ghassem, A., 2009: Addressing climate information needs at the regional level, The CORDEX framework. WMO Bull (July 2009 issue)

Giorgi, F., Coppola, E., Solmon, F., Mariotti, L., Sylla, MB., Bi, X., Elguindi, N., Diro, GT., Nair, V., Giuliani, G., Turuncoglu, UU., Cozzini, S., Güttler, I., O’Brien, TA., Tawfik, AB., Shalaby, A., Zakey, AS., Steiner, AL., Stordal, F., Sloan, LC., Branković, C., 2012: RegCM4: model description and preliminary tests over multiple CORDEX domains. Climat. Res. 52, 7-29. https://doi.org/10.3354/cr01018

Giorgi, F., Torma, Cs., Coppola, E., Ban, N., Schär, C., Somot, S., 2016: Enhanced summer convective rain at Alpine high elevations in response to climate warming. Nat. Geosci. 9, 584-589. https://doi.org/10.1038/ngeo2761

Halenka, T., 2007: On the Assessment of Climate Change Impacts in Central and Eastern Europe - EC FP6 Project CECILIA. Geophys. Res. Abst. 9, 10545.

Haylock, M.R., Hofstra, N., Tank, AMG., Klok, E.J., Jones, P.D., and New, M., 2008: A European daily high-resolution gridded dataset of surface temperature and precipitation for 1950-2006. J. Geophys. Res. (Atmospheres) 113 (D20119): 12. https://doi.org/10.1029/2008 JD10201

Hewitt, C.D. and Griggs, D., 2004: Ensembles-Based Predictions of Climate Changes and Their Impacts. Eos Trans. AGU, 85(52). https://doi.org/10.1029/2004EO520005

IPCC, 2013: Climate Change 2013: The Physical Science Basis. Contribution of Working Group I to the Fifth Assessment Report of the Intergovernmental Panel on Climate Change (eds. Stocker, T.F., D. Qin, G.-K. Plattner, M. Tignor, S.K. Allen, J. Boschung, A. Nauels, Y. Xia, V. Bex and P.M. Midgley). Cambridge University Press, Cambridge, United Kingdom and New York, NY, USA. https://doi.org/10.1017/CBO9781107415324

Jacob, D., Elizalde, A., Haensler, A., Hagemann, S., Kumar, P., Podzun, R., Rechid, D., Remedio, A.R., Saeed, F., Sieck, K., Teichmann, C., and Wilhelm, C., 2012: Assessing the transferability of the regional climate model REMO to different coordinated regional climate downscaling experiment (CORDEX) regions. Atmosphere 3, 181-199. https://doi.org/10.3390/atmos3010181

Jacob, D., Petersen, J., Eggert, B., Alias, A., Christensen, O.B., Bouwer, L.M., Braun, A., Colette, A., Déqué, M., Georgievski, G., Georgopoulou, E., Gobiet, A., Menut, L., Nikulin, G., Haensler, A., Hempelmann, N., Jones, C., Keuler, K., Kovats, S., Kröner, N., Kotlarski, S., Kriegsmann, A., Martin, E., van Meijgaard, E., Moseley, C., Pfeifer, S., Preuschmann, S., Radermacher, C., Radtke, K., Rechid, D., Rounsevel, M., Samuelsson, P., Somot, S., Soussana, J.-F., Teichmann, C., Valentini, R., Vautard, R., Weber, B., and 
Yiou, P., 2013: EURO-CORDEX: new high resolution climate change projections for European impact research. Reg. Environ. Change 14, 563-578.

https://doi.org/10.1007/s10113-013-0499-2

Jones, C., Giorgi, F., and Asrar, G., 2011: The coordinated regional downscaling experiment: CORDEX. An international downscaling link to CMIP5. CLIVAR Exch 16, 34-40.

Karl, T.R., Nicholls, N., and Ghazi, A., 1999: CLIVAR/GCOS/WMO workshop on indices and indicators for climate extremes: workshop summary. Clim. Change 42, 3-7. https://doi.org/10.1023/A:1005491526870

Kis, A., Pongrácz, R., and Bartholy, J., 2017: Multi-model analysis of regional dry and wet conditions for the Carpathian Region. Int. J. Climatol. 37, 4543-4560. https://doi.org/10.1002/joc.5104

Kotlarski, S., Paul, F., and Jacob, D., 2010: Forcing a Distributed Glacier Mass Balance Model with the Regional Climate Model REMO. Part I: Climate Model Evaluation. J. Climate 23, 1589-1606. https://doi.org/10.1175/2009JCLI2711.1

Kotlarski, S., Szabó, P., Herrera, S., Räty, O., Keuler, K., Soares, P. M., Cardoso, R. M., Bosshard, T., Pagé, C., Boberg, F., Gutiérrez, J. M., Isotta, F. A., Jaczewski, A., Kreienkamp, F., Liniger, M. A., Lussana, C., and Pianko-Kluczyńska, K., 2017: Observational uncertainty and regional climate model evaluation: a pan-European perspective. Int. J. Climatol. https://doi.org/10.1002/joc.5249

Kupiainen, M., Samuelsson, P., Jones, C., Jansson, C., Willén, U., Hansson, U., Ullerstig, A., Wang, S., and Döscher, R., 2011: Rossby centre regional atmospheric model, RCA4. Rossby Centre Newsletter.

Laprise, R., de Elía, R., Caya, D., Biner, S., Lucas-Picher, P., Diaconescu, E., Leduc, M., Alexandru, A., and Separovic, L., 2008: Challenging some tenets of Regional Climate Modelling, Meteorol. Atmos. Phys. 100, 3-22. https://doi.org/10.1007/s00703-008-0292-9

Legates, D.R. and Willmott, C. J., 1990: Mean seasonal and spatial variability in gaugecorrected, global precipitation. Int. J. Climatol. 10, 111-127.

Meijgaard, E. van, Ulft, L.H. van, Lenderink, G., Roode, S.R. de, Wipfler, E.L., Boers, R., and Timmermans, R.M.A. van, 2012: Refinement and application of a regional atmospheric model for climate scenario calculations of Western Europe. Climate Changes Spatial Planning Publication: KvR 054/12.

Peterson, T.C., Folland, C., Gruza, G., Hogg, W., Mokssit, A., and Plummer, N., 2001: Report on the activities of the working group on climate change detection and related rapporteurs 1998-2001. World Meteorological Organisation Rep. WCDMP-47, WMO-TD 1071, Geneva, Switzerland.

Prein, A.F. and Gobiet, A., 2017: Impacts of uncertainties in European gridded precipitation observations on regional climate analysis. Int. J. Climatol. 37, 305-327. https://doi.org/10.1002/joc.4706

Rockel, B., Castro, C.L., Pielke, R.A. Sr, von Storch, H., and Lencini, G., 2008: Special issue regional climate modelling with COSMO-CLM (CCLM). Meteorol Z 17, 347-348. https://doi.org/10.1127/0941-2948/2008/0309

Ruti, PM., Somot, S., Giorgi, F., Dubois, C., Flaounas, E., Obermann, A., Dell'Aquila, A., Pisacane, G., Harzallah, A., Lombardi, E., Ahrens, B., Akhtar, N., Alias, A., Arsouze, T., Aznar, R., Bastin, S., Bartholy, J., Béranger, K., Beuvier, J., Bouffies-Cloché, S., Brauch, J., Cabos, W., Calmanti, S., Calvet, J-C., Carillo, A., Conte, D., Coppola, E., Djurdjevic, V., Drobinski, P., Elizalde-Arellano, A., Gaertner, M., Galàn, P., Gallardo, C., Gualdi, S., Goncalves, M., Jorba, O., Jordà, G., L'Heveder, B., Lebeaupin-Brossier, C., Li, L., Liguori, G., Lionello, P., Maciàs, D., Nabat, P., Onol, B., Raikovic, B., Ramage, K., Sevault, F., Sannino, G., Struglia, MV., Sanna, A., Torma, Cs., and Vervatis., V., 2016: MED-CORDEX initiative for Mediterranean Climate studies, Bull. Amer. Meteor. Soc. 97, 1187-1208. https://doi.org/10.1175/BAMS-D-14-00176.1 
Separovic, L., de Elía, R., and Laprise, R., 2008: Reproducible and irreproducible components in ensemble simulations of a regional climate model. Clim. Dynam. 136, 4942-4961. https://doi.org/10.1175/2008MWR2393.1

Sillmann, J., Kharin, V.V., Zwiers, F.W., Zhang, X., and Bronaugh, D., 2013: Climate extreme indices in the CMIP5 multi-model ensemble: Part 2. Future climate projections. $J$. Geophys. Res. Atmos., 118, 2473-2493. https://doi.org/10.1002/jgrd.50188

Skamarock, W.C., Klemp, J.B., Dudhia, J., Gill, D.O., Duda, M.G., Huang, X-Y., Wang, W., and Powers, J.G., 2008: A description of the advanced research WRF version 3. NCAR Technical note 475.

Spinoni, J., Szalai, S., Szentimrey, T., Lakatos, M., Bihari, Z., Nagy, A., Németh, Á., Kovács, T., Mihic, D., Dacic, M., Petrovic, P., Kržǐcc, A., Hiebl, J., Auer, I., Milkovic, J., Štepánek, P., Zahradnicek, P., Kilar, P., Limanowka, D., Pyrc, R., Cheval, S., Birsan, M.-V., Dumitrescu, A., Deak, G., Matei, M., Antolovic, I., Nejedlik, P., Štastn'y, P., Kajaba, P., Bochnicek, O., Galo, D., Mikulová, K., Nabyvanets, Y., Skrynyk, O., Krakovska, S., Gnatiuk, N., Tolasz, R., Antofie, T., and Vogt, J., 2015: Climate of the Carpathian region in the period 1961-2010: climatologies and trends of 10 variables. Int. J. Climatol. 35, 1322-1341. https://doi.org/10.1002/joc.4059

Szalai, S., Auer, I., Hiebl, J., Milkovich, J., Radim, T., Stepanek, P., Zahradnicek, P., Bihari, Z., Lakatos, M., Szentimrey, T., Limanowka, D., Kilar, P., Cheval, S., Deak, Gy., Mihic, D., Antolovic, I., Mihajlovic, V., Nejedlik, P., Stastny, P., Mikulova, K., Nabyvanets, I., Skyryk, O., Krakovskaya, S.,Vogt, J., Antofie, T., and Spinoni, J., 2013: Climate of the Greater Carpathian Region. Final Technical Report. http://www.carpatclim-eu.org

Szentimrey, T. and Bihari, Z., 2006: MISH (Meteorological Interpolation based on Surface Homogenized Data Basis). COST Action 719 Final Report, The use of GIS in climatology and meteorology, Edited by Ole Einar Tveito, Martin Wegehenkel, Frans van der Wel and Hartwig Dobesch, 2006, 54-56.

Szentimrey, T., 2007: Manual of homogenization software MASHv3.02. Hungarian Meteorological Service.

Szépszó, G., Lingemann, I., Klein, B., and Kovács, M., 2014: Impact of climate change on hydrological conditions of Rhine and Upper Danube rivers based on the results of regional climate and hydrological models. Nat Hazards 72, 241-262. https://doi.org/10.1007/s11069-013-0987-1

Taylor, K.E., 2001: Summarizing multiple aspects of model performance in a single diagram. J. Geophys. Res. 106, 7183-7192. https://doi.org/10.1029/2000JD900719

Torma Cs., Coppola, E., Giorgi, F., Bartholy, J., and Pongrácz, R., 2011: Validation of a high resolution version of the regional climate model RegCM3 over the Carpathian Basin. $J$. Hydrometeor. 12, 84-100. https://doi.org/10.1175/2010JHM1234.1

Torma, Cs., Giorgi, F., and Coppola, E., 2015: Added value of regional climate modeling over areas characterized by complex terrain - Precipitation over the Alps. J. Geophys. Res. Atmos., 120, 3957-3972. https://doi.org/10.1002/2014JD022781

UNEP, 2007: Carpathian environmental outlook-KEO2007. United Nations Environment Programme.

Zhao, Z.-C., Luo, Y., and Huang, J.-B., 2013: A review on evaluation methods of climate modeling. Adv. Clim. Change Res., 4, 137-144.

https://doi.org/10.3724/SP.J.1248.2013.137 